\title{
The spatial distribution characteristics of soil salinity in coastal zone of the Yellow River Delta
}

\author{
Junbao Yu • Yunzhao Li • Guangxuan Han • \\ Di Zhou $\cdot$ Yuqin Fu $\cdot$ Bo Guan · Guangmei Wang • \\ Kai Ning $\cdot$ Huifeng $\mathrm{Wu} \cdot$ Jihong Wang
}

Received: 19 March 2013/Accepted: 24 November 2013/Published online: 6 December 2013

(C) The Author(s) 2013. This article is published with open access at Springerlink.com

\begin{abstract}
In coastal area, salinization is a common and serious problem for crop cultivation and ecological restoration of degraded wetlands. Therefore, the soil salinity has attracted increasing attention from farmers, government and environmental scientists. The factors controlling the soil salinity distribution have become a hot point in saline soil studies. In this study, statistics and geostatistics were used to explore the distribution of soil salinity in the Yellow River Delta (YRD) based on 150 soil samples that were collected in June 2010. Besides the experimental work, a geographical information system technique was adopted in this study. The results showed that the soil salinity ranged from 0.11 to $10.50 \mathrm{dS} \mathrm{m}^{-1}$ and the salinity in topsoil was higher than that in subsoil in the YRD, indicating that the salt in subsoil moved up and
\end{abstract}

J. Yu (ه) · Y. Li · G. Han · D. Zhou · Y. Fu · B. Guan ·

G. Wang $\cdot$ K. Ning $\cdot$ H. Wu

Key Laboratory of Coastal Zone Environmental Processes and Ecological Remediation, Yantai Institute of Coastal Zone

Research (YIC), Chinese Academy of Sciences, Yantai 264003,

People's Republic of China

e-mail: junbao.yu@gmail.com; jbyu@yic.ac.cn

J. Yu · Y. Li · G. Han - D. Zhou · Y. Fu · B. Guan · G. Wang ·

K. Ning $\cdot \mathrm{H}$. Wu

Shandong Provincial Key Laboratory of Coastal Zone

Environmental Processes, YICCAS, Yantai 264003,

People's Republic of China

Y. Li · D. Zhou · Y. Fu - K. Ning

University of Chinese Academy of Sciences, Beijing 100049,

People's Republic of China

J. Wang

Jilin Agricultural University, Changchun 130118,

People's Republic of China accumulated in topsoil as a function of evaporation. There was a significant difference among soil salinity spatial variances from different soil depths in the YRD. Generally, soil salinity of the topsoil was higher than that of the subsoil. Meanwhile, there were significant positive correlations in soil salinity between different soil depths. In addition, landforms, land uses, soil types and soil texture were important factors affecting soil salinity. The current distribution of soil salinity resulted from the comprehensive effects of anthropogenic activities and natural processes. The present study results suggest that the impacts of human activities were critical factors for salt redistribution in the coastal wetlands, which should be valuable for agricultural management and ecological restoration in the YRD.

Keywords Soil salinity · Distribution · Impact factor · Geographical information system · Yellow River Delta

\section{Introduction}

The physical, chemical and mechanical properties of soil were impacted greatly by salts, especially the soluble salts. Salts can be transported from a salt laden water table to soil surface by capillary rise due to evaporation. Human activities such as irrigation with saline water can also make salts concentrated rapidly on the surface of soil and intensify the soil salinization (Wang et al. 2002; Ben Ahmed et al. 2012). Salinization might not be so devastating as earthquakes, volcanic eruption or large-scale landslides, but it is certainly a severe environmental hazard (Metternicht and Zinck 2003). Salinities of $0.7 \mathrm{dS} \mathrm{m}^{-1}$ $\left(\mathrm{EC}_{\mathrm{e}}\right.$ value) or less are generally not stressful to most plants 
(Kotuby-Amacher et al. 1997). Above this threshold, however, the dissolved salts can induce an osmotic stress in the organisms (Thomas and Wiegand 1970). Therefore, the soil salinization greatly threatens the normal growth of plant and creates a serious problem for agriculture, which has been of great concerns for farmers, government and environmental scientists.

Coastal zone is an interface between the land and ocean. There is a continuous supplement of salts from seawater into mudflats and salt marsh in coastal area. Moreover, there are heavy human activities in coastal area, which may influence salts migration to inland soil. Actually, soil salinity is one of the two particular stress factors influencing the growth of plants and crops in coastal area, the other is the soil alkali (Hussein and Rabenhorst 2001; Arun and Sridhar 2005). The Yellow River Delta (YRD) is a low gradient floodplain and the transitional zone of the Bohai Sea and the North China plain. Massive sediment is transported from the Loess Plateau to the YRD by the Yellow River, causing the expansion of YRD by 20-25 $\mathrm{km}^{2}$ per year (Ren and Walker 1998). The YRD is easily influenced by salts from seawater because of low elevation. Short freshwater supply leads to the seawater intrusion. Furthermore, the high ratio of evaporation to precipitation (Guan et al. 2001a, b; Guan and Liu 2003) and salt-loaded aerosols (Zarroca et al. 2011) are reasons for top soil salinization as well. Therefore, large area of saline soil appeared in the YRD (Li et al. 2003). In addition, the disorderly reclamation of farmland and extensive field management increase the secondary soil salinization. It is estimated that nearly half $(47.4 \%)$ of the land in the YRD was salt affected, of which more than 66,500 ha was heavy saline land in 2001 (Guan et al. 2001a, b). The basic spatial distribution of soil salinity in the YRD is strip or block pattern on land surface (Yao et al. 2006) and salts are gathered on topsoil (Liu et al. 2010). The main factors related to soil salinity include soil type (Fang et al. 2005), water quality (Chhabra 1996), landform (Fang et al. 2005), soil texture (Wang et al. 2012), water table position (Northey et al. 2006), irrigation (Hoffman and Bresler 1986; Fan et al. 2010; Huang et al. 2011; Basile et al. 2012) and land use (Celik 2005; Zhang et al. 2011). Although some simulation models were used to explore the spatial distribution and influencing factors of soil salinity (Fan et al. 2010; Zhang et al. 2011), the spatial distribution of soil salts and their impact factors on the YRD are not clear. In this study, statistical methods coupled with geostatistical methods were used to explore the distribution of soil salinity in the YRD. The objectives of this study were (1) to explore the difference in soil salinity in different land uses, landforms, soil types and soil texture, and (2) to reveal the characteristics of spatial pattern of soil salinity in the YRD.

\section{Materials and methods}

Description of the study area

The study area is located in the modern YRD which is situated at the northeast of Shandong province, China (Ye et al. 2007). Because of rich sediment in river water, the Yellow River had changed its delta channel (about $100 \mathrm{~km}$ from the mouth) for nine times, and the river mouth had varied over a range of $100 \mathrm{~km}$ from its present position from 1855 to 1976 (Yu et al. 2011). The current channel (Qingshuigou channel), resulted from artificial geo-engineering in 1976 and a minor shift of the mouth channel in 1996, was the current prime outlet to the sea (Yu et al. 2011). The Yellow River Delta has been divided into the north sub-delta and the south sub-delta by Qingshuigou channel (Fig. 1). Because of short soil formation processes and high soil salinity, the content of soil nutrient in the YRD is definitely low (Yu et al. 2010).

The regional climate is a temperate semi-humid continental monsoon climate. The average annual precipitation is $530-630 \mathrm{~mm}$, of which $70 \%$ is in the summer (Fang et al. 2005; Zhang et al. 2009). The average annual evaporation is $1,900-2,400 \mathrm{~mm}$ (Zhao et al. 2010). The altitude of the YRD is low and most parts are $<10 \mathrm{~m}$ in elevation. The study area is a flat floodplain with a plain slope of 0.0001 (Shi et al. 2003). There are six landform types and eight land cover types in the YRD (Xu 1997). Cotton and corn fields mainly distribute in the inland area and the pasture, grassland and planted forest (Robinia pseudoacacia and Salix matsudana Koidz.) distribute in the central part. The swamp and salt marsh are widespread in the north and east part of the YRD where there are less human activities. The dominant species in the coastal wetland ecosystem are Phragmites australis, Tamarix chinensis and Suaeda salsa.

\section{Data collecting and processing}

The geographical information on land uses, soil texture, landforms and soil types was used to analyze the impact of geographical conditions on soil salinity distribution. The soil data were digitized from soil maps of the YRD (Liu and Drost 1997). By considering the morphological changes of the YRD caused by sediment deposition of the Yellow River and coastal erosion in the last decade, the coastline of the YRD in the soil maps was modified based on field survey and means of interpretation of aerial photographs. According to Food and Agriculture Organization (FAO) soil classification, the dominant soil types are Calcaric Fluvisols, Gleyic Solonchaks and Salic Fluvisols in the study area. The Calcaric Fluvisols mainly distribute along river channel. The Gleyic Solonchaks are common 


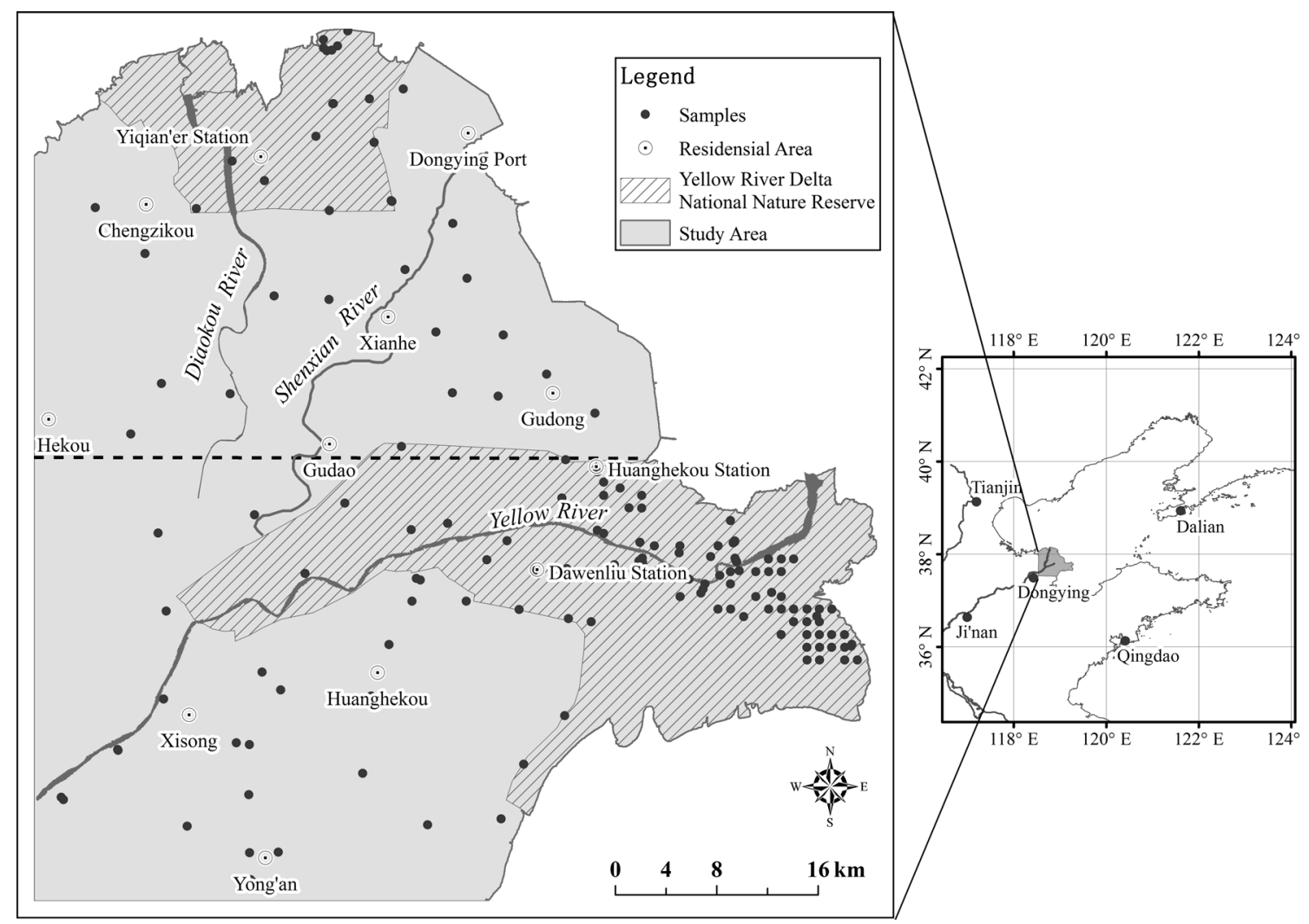

Fig. 1 The location of the Yellow River Delta and sample sites

along the seashore where the dominant land type is salt marsh and the Salic Fluvisols distribute in the transitional zone of floodplain and salt marsh (Fig. 2a).

Based on land use and land cover, the land-use map of the YRD was produced using supervised maximum likelihood classification from Landsat Thematic Mapper data (Fig. 2b). The land-use types included farmland (cotton, corn and soybean fields), forest, shrub, meadow, salt marsh, open water, aquaculture and residential area. Farmland mainly distributes in the central and western parts of the YRD. Shrub and meadow were widespread in the low-lying drainage basin and river bank, while aquaculture and salt marsh were limited to the coastal zone. Although each type of land uses was well defined, borders of different land uses were fuzzy especially in some area with high vegetation coverage. Therefore, the border was not well clear in above area and was defined basically by field survey.

The landform data were digitized from the morphological map which was drawn by the Institute of Geology Environment Monitoring of China in 2005. There were six geomorphic types in the YRD (Fig. 2c). Fluvial uplands mainly distributed in the abandoned river channel, the flood plain appeared in the present river channel. Low-lying drainage basin was widely spread in the central part of the delta, the tidal flats, salt marsh and coastal low-lying plain mainly distributed along coastline. Isolated depression had a fragmentized distribution in the center of the delta.

According to the classification of the United States Department of Agriculture, the soil texture was digitized from soil texture maps of the YRD (Liu and Drost 1997). To test the accuracy of the map, the soil particle size of 10 collected soil samples were examined by laser particle analyzer (Marlvern Mastersizer 2000F). In the YRD, types of soil texture included sandy loam, sandy clay loam, clayey loam, silty clay and clay (Fig. 2d), of which sandy loam was the most widely distributed.

A total of 150 soil sampling sites were selected by grid method in the study area, of which 82 were located in the Yellow River Delta National Nature Reserve (YRDNNR), which were located in the southeast part of the YRD where the Yellow River meets the Bohai Sea. The soil was sampled in June 2010 and the coordinate information of sample sites was recorded (Fig. 1). At each site, soil samples of three different depths of $0-10,10-20$ and $20-30 \mathrm{~cm}$ were collected. Then a mixture of soil in the three soil depths (ratio 1:1:1) was prepared to represent the $0-30 \mathrm{~cm}$ soil depth. All of the collected soil samples were used to prepare a 1:5 soilwater suspensions to detect the soil salinities (Sampford 1962; Cetin and Kirda 2003a, b; Spies and Woodgate 2005). The monitored electrical conductivity $(\mathrm{EC})$ value $\left(\mathrm{dS} \mathrm{m}{ }^{-1}\right.$, 

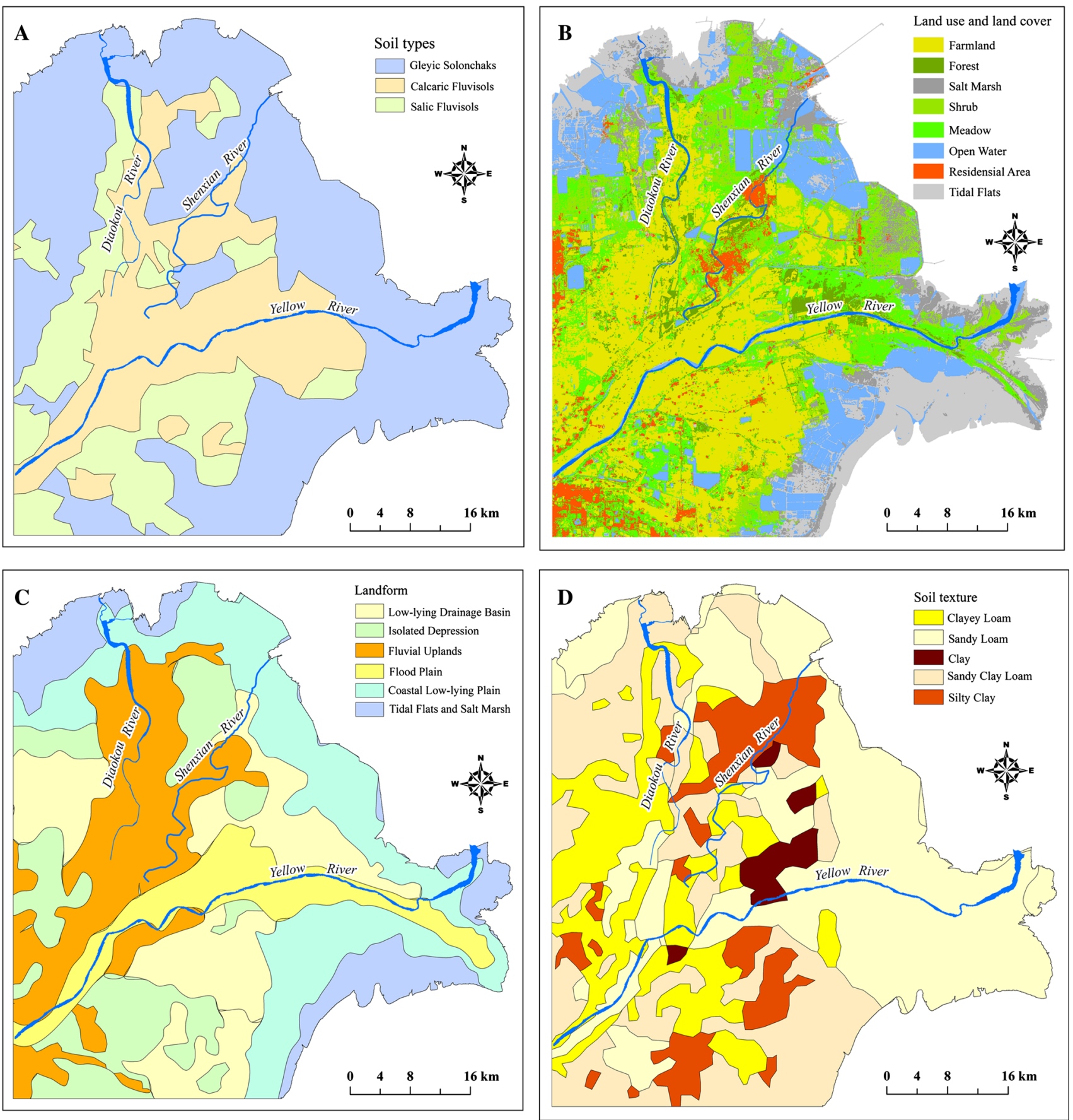

Fig. 2 Geographical information on soil types (a), land uses (b) landform (c) and soil texture (d) of the Yellow River Delta

$25^{\circ} \mathrm{C}$ ) was used to display the soil salinities because the EC has been regarded as a good indicator of the total soluble salinity (Rhoades and van Schilfgaarde 1976; Williams and Hoey 1987; Rhoades et al. 1989a, b).

\section{Data analyses}

Descriptive statistics were performed to analyze the general characteristics of soil salinity and one-way analysis of variance (ANOVA) was used to evaluate the differences in soil salinities between landforms, land uses, soil types and soil texture, respectively (Fang et al. 2005). Relationships of EC value between different soil depths were analyzed by the correlation analysis. Then the geostatistical methods of ordinary kriging was performed to explore the spatial distribution of soil salinity (Cetin and Kirda 2003a, b). Spatial analysis methods, including extraction and reclassification, were also used to draw the salinity map. The statistical 
analysis were conducted using SPSS version 18.0 (Carver and Nash 2011), while the geostatistics and spatial analyses were conducted with ARCGIS version 9.3 (Johnston 2004; Cassel 2007).

\section{Results}

Distribution of soil salinity in different landforms, land uses, soil types and soil texture

The average soil salinity in 0-30 cm soil depth in the YRD was $2.31 \pm 0.09 \mathrm{dS} \mathrm{m}^{-1}$ (Table 1). The average soil salinity in soil depth of 0-10, 10-20 and 20-30 cm was $2.83 \pm 0.19, \quad 2.05 \pm 0.11$ and $2.05 \pm 0.12 \mathrm{dS} \mathrm{m}^{-1}$, respectively (Table 1 ). The highest average value of the $0-30 \mathrm{~cm}$ soil salinity $\left(3.27 \pm 0.15 \mathrm{dS} \mathrm{m}^{-1}\right)$ appeared in the coastal low-lying plain and the lowest $\left(1.60 \pm 0.16 \mathrm{dS} \mathrm{m}^{-1}\right)$ value appeared in the isolated depression (Table 2; Fig. 3a). Soil salinity in the coastal low-lying plain, tidal flats and salt marsh was much higher than that in the isolated depression, fluvial uplands and flood plain regardless of $0-10,10-20$ or $20-30 \mathrm{~cm}$ soil depth (Table 2; Fig. 3a). The ANOVA test showed that there were significant differences in soil salinity among different landforms (Table 3; Fig. 3a).

The land use is an important factor impacting the salts distribution in coastal zone. In the present study, salinity of the $0-30 \mathrm{~cm}$ soil depth in salt marsh was the highest $\left(3.17 \pm 0.13 \mathrm{dS} \mathrm{m}^{-1}\right)$ and was three times more than that of forest $\left(0.90 \pm 0.34 \mathrm{dS} \mathrm{m}^{-1}\right)$ (Table 2; Fig. 3b). Salinity of each soil depth in salt marsh and shrub was relatively higher than that of other lands (Table 2; Fig. 3b). There were significant differences in soil salinity in $0-30 \mathrm{~cm}$

Table 1 Descriptive statistics for soil salinity (EC value, $\mathrm{dS} \mathrm{m}^{-1}$ ) in each soil depth

\begin{tabular}{|c|c|c|c|c|c|c|c|c|c|}
\hline \multirow[t]{2}{*}{ Soil depths (cm) } & \multicolumn{3}{|l|}{ YRD } & \multicolumn{3}{|c|}{ The south sub-delta } & \multicolumn{3}{|c|}{ The north sub-delta } \\
\hline & Mean \pm S.E. & Min & $\operatorname{Max}$ & Mean \pm S.E. & Min & Max & Mean \pm S.E. & Min & Max \\
\hline $0-30$ & $2.31 \pm 0.09$ & 0.11 & 10.5 & $2.35 \pm 0.10$ & 0.13 & 10.5 & $2.16 \pm 0.18$ & 0.11 & 9.86 \\
\hline $0-10$ & $2.83 \pm 0.19$ & 0.11 & 10.5 & $2.94 \pm 0.21$ & 0.13 & 10.5 & $2.36 \pm 0.45$ & 0.11 & 9.86 \\
\hline $10-20$ & $2.05 \pm 0.11$ & 0.13 & 5.99 & $2.07 \pm 0.13$ & 0.13 & 5.99 & $2.00 \pm 0.21$ & 0.15 & 5.14 \\
\hline $20-30$ & $2.05 \pm 0.12$ & 0.15 & 8.27 & $2.04 \pm 0.14$ & 0.15 & 8.27 & $2.12 \pm 0.22$ & 0.27 & 5.58 \\
\hline
\end{tabular}

Table 2 Average and standard error of soil salinity $\left(\mathrm{dS} \mathrm{m}^{-1}\right)$ in different landforms (A), land uses (B), soil types (C) and soil texture

\begin{tabular}{|c|c|c|c|c|c|c|}
\hline \multirow[t]{2}{*}{ Geographical factors } & \multirow[t]{2}{*}{ Subclass of geographical factors } & \multirow[t]{2}{*}{ Observations } & \multicolumn{4}{|c|}{ Soil depths (cm) } \\
\hline & & & $0-30$ & $0-10$ & $10-20$ & $20-30$ \\
\hline \multirow[t]{6}{*}{ Landform } & Coastal low-lying plain & 49 & $3.27 \pm 0.15$ & $4.11 \pm 0.34$ & $2.89 \pm 0.19$ & $2.81 \pm 0.19$ \\
\hline & Tidal flats and salt marsh & 7 & $2.92 \pm 0.25$ & $3.58 \pm 0.60$ & $2.63 \pm 0.26$ & $2.57 \pm 0.27$ \\
\hline & Low-lying drainage basin & 27 & $1.78 \pm 0.16$ & $2.20 \pm 0.37$ & $1.70 \pm 0.25$ & $1.44 \pm 0.19$ \\
\hline & Isolated depression & 13 & $1.60 \pm 0.16$ & $1.65 \pm 0.34$ & $1.48 \pm 0.25$ & $1.67 \pm 0.29$ \\
\hline & Fluvial uplands & 8 & $1.75 \pm 0.36$ & $1.74 \pm 0.81$ & $1.69 \pm 0.54$ & $1.84 \pm 0.57$ \\
\hline & Flood plain & 46 & $1.82 \pm 0.15$ & $2.27 \pm 0.32$ & $1.51 \pm 0.18$ & $1.68 \pm 0.26$ \\
\hline \multirow[t]{5}{*}{ Land use } & Meadow & 46 & $1.81 \pm 0.12$ & $2.04 \pm 0.27$ & $1.65 \pm 0.16$ & $1.75 \pm 0.20$ \\
\hline & Shrub & 31 & $3.05 \pm 0.23$ & $3.76 \pm 0.55$ & $2.75 \pm 0.30$ & $2.65 \pm 0.28$ \\
\hline & Farmland & 25 & $1.14 \pm 0.12$ & $1.39 \pm 0.27$ & $1.00 \pm 0.17$ & $1.04 \pm 0.18$ \\
\hline & Forest & 5 & $0.90 \pm 0.34$ & $1.07 \pm 0.84$ & $0.94 \pm 0.61$ & $0.69 \pm 0.38$ \\
\hline & Salt marsh & 43 & $3.17 \pm 0.13$ & $4.06 \pm 0.24$ & $2.73 \pm 0.16$ & $2.70 \pm 0.21$ \\
\hline \multirow[t]{3}{*}{ Soil type } & Gleyic Solonchaks & 107 & $2.61 \pm 0.10$ & $3.20 \pm 0.23$ & $2.32 \pm 0.14$ & $2.32 \pm 0.15$ \\
\hline & Calcaric Fluvisols & 27 & $1.86 \pm 0.17$ & $2.25 \pm 0.38$ & $1.65 \pm 0.24$ & $1.66 \pm 0.26$ \\
\hline & Salic Fluvisols & 16 & $1.09 \pm 0.13$ & $1.37 \pm 0.31$ & $0.95 \pm 0.15$ & $0.95 \pm 0.15$ \\
\hline \multirow[t]{5}{*}{ Soil texture } & Sandy clay loam & 21 & $2.08 \pm 0.22$ & $2.54 \pm 0.53$ & $1.86 \pm 0.28$ & $1.84 \pm 0.29$ \\
\hline & Sandy loam & 110 & $2.41 \pm 0.10$ & $2.98 \pm 0.22$ & $2.13 \pm 0.13$ & $2.12 \pm 0.15$ \\
\hline & Clay & 5 & $3.08 \pm 0.58$ & $4.57 \pm 1.18$ & $2.62 \pm 0.84$ & $2.05 \pm 0.47$ \\
\hline & Clayey loam & 5 & $2.20 \pm 0.54$ & $2.30 \pm 1.24$ & $1.94 \pm 0.84$ & $2.37 \pm 0.90$ \\
\hline & Silty clay & 9 & $1.45 \pm 0.19$ & $1.41 \pm 0.40$ & $1.42 \pm 0.27$ & $1.53 \pm 0.34$ \\
\hline
\end{tabular}



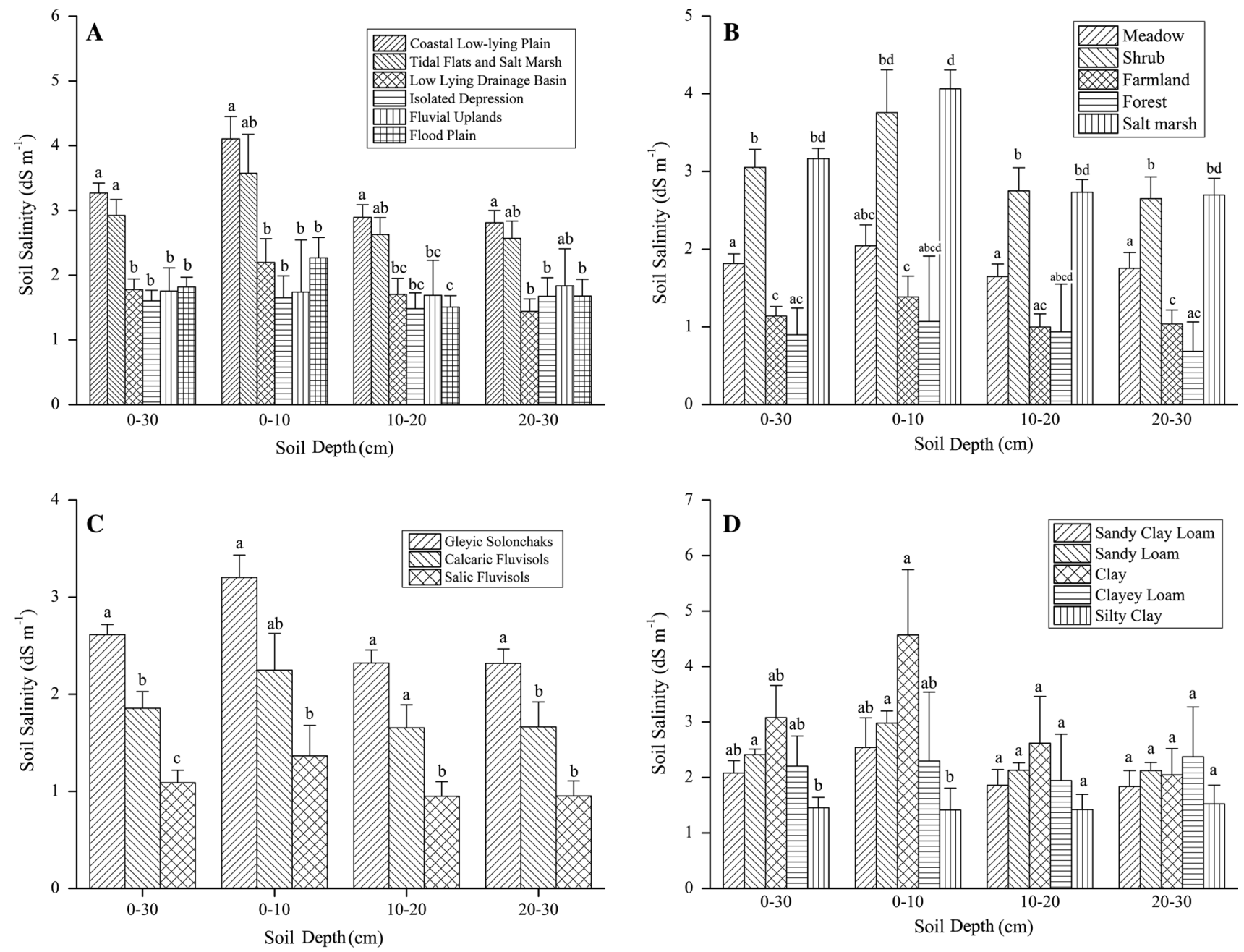

Fig. 3 Soil salinity distribution in different landforms (a), land uses (b), soil types (c) and soil texture (d). Letters above error bar of each column indicate significantly different means at the $p<0.05$ level for multiple comparisons, vertical bar means standard error

depth among different land uses as revealed by one-way ANOVA test (Table 3; Fig. 3b). Similar results were also observed in $0-10,10-20$ and $20-30 \mathrm{~cm}$ soil depths (Table 3; Fig. 3b).

Soil salinity in Gleyic Solonchaks, Calcaric Fluvisols and Salic Fluvisols showed a similar ladder shape with a descending trend in each soil depth. Soil salinity of Gleyic Solonchaks was two times more than that of Salic Fluvisols, which was the lowest in different soil types in all soil depths (Table 2; Fig. 3c). Results of ANOVA showed that there were significant differences in soil salinity among different soil types in each soil depth (Table 3; Fig. 3c).

Soil salinities in clay were relatively higher than that in sandy clay loam, clayey loam, sandy loam and silty clay regardless of the $0-10,10-20,20-30$ and $0-30 \mathrm{~cm}$ soil depths (Table 2; Fig. 3d). Results of the post hoc analysis showed that there were significant differences of $0-30 \mathrm{~cm}$ soil salinity among different soil texture. However, soil salinity from different soil texture in the $0-10,10-20$ and
20-30 cm depths showed no significant differences individually. (Table 2; Fig. 3d).

The spatial distribution characteristics of soil salinity in the YRD

In the interpolated map of soil salinity of the $0-10 \mathrm{~cm}$ soil depth, high soil salinity generally distributed in the coastal area and the central part of the YRD, while low soil salinity mainly distributed on both banks of the Yellow River and southwest part of the YRD (Fig. 4a). The interpretation map of soil salinity of the 10-20 and 20-30 cm soil depths showed a similar spatial pattern that high soil salinity area was mainly distributed in the coastal area, while soil salinity in the majority of inner part of the YRD was $<2 \mathrm{dS} \mathrm{m}^{-1}$ (Fig. 4b, c).

Differences of the soil salinity between the south and north sub-delta were not significant regardless of soil depth (Table 3; Fig. 5a). However, the average EC value of the 
Table 3 ANOVA test results for soil salinity in different soil types, soil textures, landforms, land uses and areas

\begin{tabular}{clll}
\hline & $\begin{array}{l}\text { Soil depths } \\
(\mathrm{cm})\end{array}$ & $\begin{array}{l}F \text { value }(\text { Cedfeldt et al. } \\
2000)\end{array}$ & $P$ value \\
\hline Soil type & $0-30$ & $19.58(2,447)$ & $0.00^{*}$ \\
& $0-10$ & $5.91(2,147)$ & $0.00^{*}$ \\
& $10-20$ & $9.09(2,147)$ & $0.00^{*}$ \\
Soil & $20-30$ & $7.52(2,147)$ & $0.00^{*}$ \\
texture & $0-30$ & $2.50(4,445)$ & $0.04^{*}$ \\
& $0-10$ & $1.59(4,145)$ & 0.18 \\
& $10-20$ & $0.79(4,145)$ & 0.54 \\
Landform & $0-30$ & $0.50(4,145)$ & 0.74 \\
& $0-10$ & $16.26(5,444)$ & $0.00^{*}$ \\
& $10-20$ & $6.08(5,144)$ & $0.00^{*}$ \\
& $20-30$ & $7.55(5,144)$ & $0.00^{*}$ \\
Land use & $0-30$ & $4.93(5,144)$ & $0.00^{*}$ \\
& $0-10$ & $30.17(4,445)$ & $0.00^{*}$ \\
& $10-20$ & $11.48(4,145)$ & $0.00^{*}$ \\
Locations & $0-30$ & $13.30(4,145)$ & $0.00^{*}$ \\
& $0-30$ & $9.32(4,145)$ & $0.00^{*}$ \\
& $0-10$ & $0.37(4,145)$ & 0.69 \\
& $10-20$ & $0.72(2,297)$ & 0.49 \\
& $20-30$ & $0.03(2,297)$ & 0.98 \\
& & $0.03(2,297)$ & 0.97 \\
\hline 0.05 & & &
\end{tabular}

$* p<0.05$

$0-10 \mathrm{~cm}$ depth was significant higher than that of the 10-20 and $20-30 \mathrm{~cm}$ soil depths in the south sub-delta, while there were no significant differences in soil salinity of the north sub-delta (Fig. 5b). Moreover, soil salinities in all depths of the YRD were similar to the results of the south sub-delta (Fig. 5b). As a whole, it appeared that soil salinity of the $0-10 \mathrm{~cm}$ depth was much higher than that of the subsoil, while it changed little between the 10-20 and 20-30 cm soil depths (Fig. 5b). A significant positive correlation in the average EC values between the 0-10, 10-20 and 20-30 cm soil depths was observed (Table 4).

\section{Discussion}

It is a convenient and feasible method to detect soil salinity using EC as the indicator (Rhoades and van Schilfgaarde 1976; Rhoades et al. 1989a, b; Rhoades 1996). Based on the regression equation between $\mathrm{EC}$ value and soil salinity in the coastal area of China built by Cai et al. (1997), we estimated that the average soil salt content of the $0-30 \mathrm{~cm}$ depth in the YRD was approximately $6 \mathrm{~g} \mathrm{~kg}^{-1}$. The result accorded with the previous achievements (Fan et al. 2010) (Yao and Yang 2007) and implied that the YRD was facing serious salts problems. In fact, more than half of the soils in the YRD were undergone heavy salinization (Liu et al. 2006).
The distribution patterns of soil salinity in this work revealed that (1) topsoil (soil in the $0-10 \mathrm{~cm}$ soil depth) showed higher salinity than the subsoil (Table 1), (2) salinity in the coastal area was higher than that in the inland (Fig. 4), (3) soil salinity in the estuary of rivers was higher than that in the surrounding area (Fig. 4), (4) soil with finer texture showed higher salinity (Table 2), (5) areas under strong human activities seemed to experience little salinization risk (Figs. 2, 4; Table 2), and (6) there were significant positive correlations in salinity between different soil depths (Table 4). These rules were valuable for the investigation and management of salinization in the YRD. For instance, if a salt efflorescence phenomenon appears on the ground surface in the field investigation, it can be concluded that the subsoil might be saline as well. Then, corresponding measures could be considered and put into effect.

Soil salinity may be greatly affected by environmental processes and anthropogenic factors (de Leeuw et al. 1991; Cetin and Kirda 2003a, b; Yang et al. 2009; Zhang et al. 2011). The location and natural conditions of the YRD made it vulnerable to suffer salinization (Fan et al. 2010; Liu et al. 2012). Under the temperate semi-humid continental monsoon climate, the evaporation is strong in the YRD where the evaporation-precipitation ratio is about 3:1 (Guan et al. 2001a, b). Meanwhile, the YRD is a young alluvial land with high groundwater table and mineralization (Fan et al. 2010). Therefore, lots of soluble salts migrate to ground surface by evaporation resulting in salt efflorescence phenomena. In the coastal area of the YRD, seawater intrusion is a serious problem for the low elevation and wide intertidal zone. Too much saline water intrudes into soil which might change the properties of soil water (Xue et al. 1997; Liu 2004). Then, soil tends towards salinization under the impacts of capillarity and evaporation. In addition, the ocean spray may suspend salts into the air as salt-loaded wind aerosols, which can be transported long distance to inland (Zarroca et al. 2011). Salt-loaded aerosols can then fall onto ground (e.g., due to the rainfall), an impact on soil salinity in near shore area (Team 2004). In this study, it was found that the distribution of soil salinity was related to geomorphology and land uses. Some studies supported this viewpoint and indicated that landform and land uses affected soil salinity by influencing the surface and subsurface runoff which changed the water-salt migration in soil (Liu et al. 2006, 2008). Soil texture, determining capillary rise, was also found to be an important factor influencing soil salinity. Generally, the finer the soil texture is, the weaker the soil leaching is (Hong and Hendrickx 2002). Thus, a finer soil texture leads to more salts accumulation in topsoil (Liu et al. 2008). In addition, as the major source of fresh water in the YRD, the Yellow River influences the distribution of soil salinity indirectly. Farthest area from the course of the Yellow River receives 

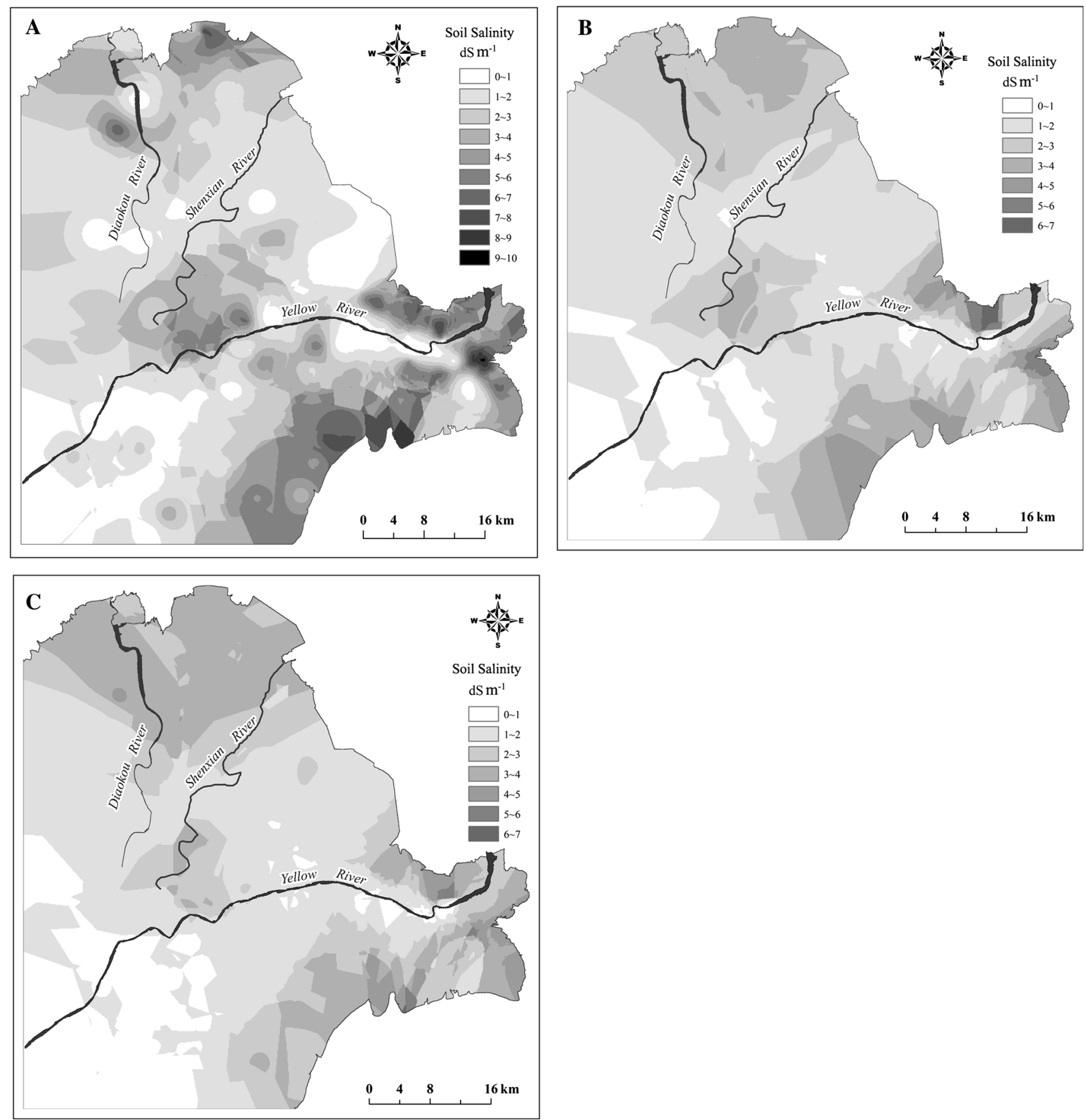

Fig. 4 The spatial distribution of soil salinity in 0-10 cm (a), 10-20 cm (b) and 20-30 cm (c) soil depth

limited fresh water supply, and therefore faces great risk of salinization. Furthermore, there might be another way of contribution in the coastal saline due to the existence of levels of fine textured sediments filled of brackish congenital waters, formed in marine or in the marshes, which are actually incorporated into the continental due to the fast delta system evolution. Vegetation plays a special role in salinization as well. On one hand, the plant cover contributes to the control of soil salinity indirectly by restraining evaporation of ground surface although soil salts were proved to be a limiting factor in the growth of plants in the YRD (Wu et al. 1994). On the other hand, some salttolerant plants such as $T$. chinensis and $S$. salsa have the ability of transferring salt ions from soil to plant corpus, which might be an effective mechanism for remission of high soil salinity (Zhang et al. 2007; Guo et al. 2011; Lei 

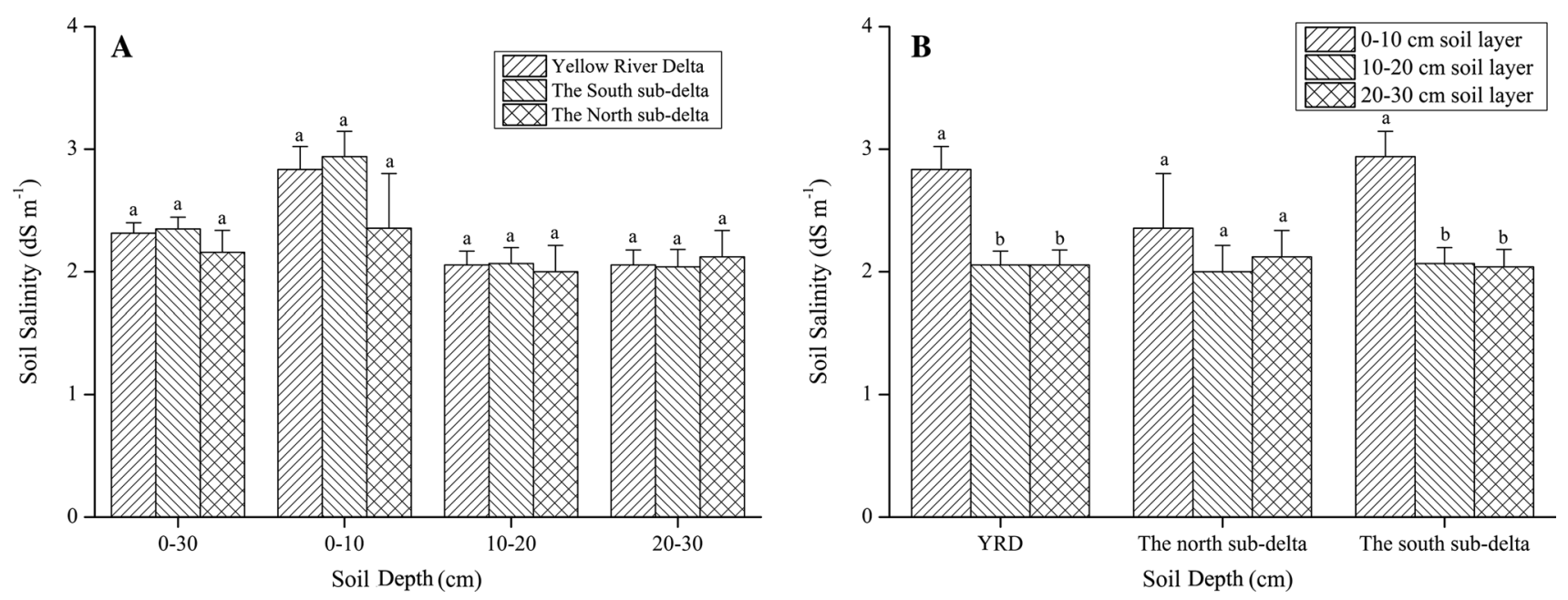

Fig. 5 Characteristics of soil salinity (Mean \pm S.E.) in soil depth (a) and different areas (b). Letters above error bar of each column indicate significantly different at the $p<0.05$ level for multiple comparisons

Table 4 Relationships of soil salinity between different soil depths

\begin{tabular}{llll}
\hline Soil depth $(\mathrm{cm})$ & $0-10$ & $10-20$ & $20-30$ \\
\hline $0-10$ & & & \\
$\quad \begin{array}{l}\text { Pearson correlation } \\
\text { Sig (tow-tailed) }\end{array}$ & 1 & $0.865^{* *}$ & $0.740^{* *}$ \\
$N$ & 150 & 150 & 0.000 \\
10-20 & & & 150 \\
$\quad$ Pearson correlation & $0.865^{* *}$ & 1 & $0.876^{* *}$ \\
Sig (tow-tailed) & 0.000 & & 0.000 \\
$N$ & 150 & 150 & 150 \\
20-30 & & & \\
Pearson correlation & $0.740^{* *}$ & $0.876^{* *}$ & 1 \\
Sig (tow-tailed) & 0.000 & 0.000 & \\
$N$ & 150 & 150 & 150 \\
\hline
\end{tabular}

$* * p<0.01$

et al. 2011). Anthropogenic activities couldn't be neglected in the study of salinization (de Leeuw et al. 1991; Wu et al. 1994; Mondal et al. 2001; Zheng et al. 2009; Zhang et al. 2011). People have developed many effective measures such as watering and salt leaching to alleviate salinization (Khosla et al. 1979; Christen and Skehan 2001; Corwin et al. 2007). Some researchers found that cultivation might be a method to control soil salinity as well (Akhter et al. 2003; Li et al. 2010). In the coastal area, people build breakwater to protect the upper tidal flat from sea water intrusion. Meanwhile, some anthropogenic activities such as unadvisable irrigation and reclamation might lead to secondary salinization (Lax et al. 1994; Dehaan and Taylor 2002; Rietz and Haynes 2003). Thus, we should take into account appropriate human activities in saline land to prevent salinization.

\section{Conclusions}

The YRD was suffering heavy salinization and high salinity generally appeared in the topsoil. Meanwhile, there were significant positive correlations in soil salinity between different soil depths. The spatial distribution pattern of soil salinity of the $0-10 \mathrm{~cm}$ depth was more sophisticated than the $10-20$ and $20-30 \mathrm{~cm}$ soil depths. The spatial distribution of soil salinity resulted from the comprehensive effects of anthropogenic activities and some natural factors. The findings of this study are expected to contribute to agricultural management and ecological restoration in the YRD.

Acknowledgments We are grateful for support from the Project of National Science \& Technology Pillar Program in "12th Five Year" period (2011BAC02B01), National Natural Science Foundation for Distinguished Young Scholar of Shandong Province (JQ201114), the National Science Foundation of China (41071160) and the CAS/ SAFEA International Partnership Program for Creative Research Teams. We thank the Yellow River Delta Ecology Research Station of Coastal Wetland, CAS, with the help of field work.

Open Access This article is distributed under the terms of the Creative Commons Attribution License which permits any use, distribution, and reproduction in any medium, provided the original author(s) and the source are credited.

\section{References}

Akhter J, Mahmood K, Malik KA, Ahmed S, Murray R (2003) Amelioration of a saline sodic soil through cultivation of a salttolerant grass Leptochloa fusca. Environ Conserv 30(02): $168-174$

Arun AB, Sridhar KR (2005) Growth tolerance of rhizobia isolated from sand dune legumes of the southwest coast of India. Eng Life Sci 5(2):134-138 
Basile A, Buttafuoco G, Mele G, Tedeschi A (2012) Complementary techniques to assess physical properties of a fine soil irrigated with saline water. Environ Earth Sci 66(7):1797-1807

Ben Ahmed C, Magdich S, Ben Rouina B, Boukhris M, Ben Abdullah F (2012) Saline water irrigation effects on soil salinity distribution and some physiological responses of field grown Chemlali olive. J Environ Manage 113:538-544

Cai AX, Chen Z, Jiang Z, Song R (1997) Relationships between salt content and electric conductivity in different saline area of China. Soils 01:54-57

Carver R, Nash JG (2011) Doing data analysis with SPSS: Version 18.0 Cengage Learning, Singapore

Cassel F (2007) Soil salinity mapping using ArcGIS. GIS Appl Agric $141-162$

Cedfeldt PT, Watzin MC, Richardson BD (2000) Using GIS to identify functionally significant wetlands in the Northeastern United States. Environ Manage 26(1):13-24

Celik I (2005) Land-use effects on organic matter and physical properties of soil in a southern Mediterranean highland of Turkey. Soil Tillage Res 83(2):270-277

Cetin M, Kirda C (2003a) Spatial and temporal changes of soil salinity in a cotton field irrigated with low-quality water. J Hydrol 272(1-4):238-249

Cetin M, Kirda C (2003b) Spatial and temporal changes of soil salinity in a cotton field irrigated with low-quality water. J Hydrol 272(1):238-249

Chhabra R (1996) Soil salinity and water quality. Taylor and Francis, Brookfield

Christen E, Skehan D (2001) Design and management of subsurface horizontal drainage to reduce salt loads. J Irrigat Drain Eng 127(3):148-155

Corwin DL, Rhoades JD, Šimůnek J (2007) Leaching requirement for soil salinity control: steady-state versus transient models. Agric Water Manag 90(3):165-180

de Leeuw J, van den Dool A, de Munck W, Nieuwenhuize J, Beeftink WG (1991) Factors influencing the soil salinity regime along an intertidal gradient. Estuar Coast Shelf Sci 32(1):87-97

Dehaan RL, Taylor GR (2002) Field-derived spectra of salinized soils and vegetation as indicators of irrigation-induced soil salinization. Remote Sens Environ 80(3):406-417

Fan X, Liu G, Tang Z, Shu L (2010) Analysis on main contributors influencing soil salinization of Yellow River Delta. J Soil Water Conserv 24(1):139-144

Fang H, Liu G, Kearney M (2005) Georelational analysis of soil type, soil salt content, landform, and land use in the Yellow River Delta, China. Environ Manage 35(1):72-83

Guan Y, Liu G (2003) Remote sensing detection of dynamic variation of the saline land in the Yellow River Delta. Remote Sensing Land Res 15(2):19-22

Guan Y, Liu G, Liu Q, Ye Q (2001a) The study of salt affected soils in the Yellow River Delta based on remote sensing. J Remote Sensing 5(1):46-52

Guan Y, Liu G, Wang J (2001b) Regionalization of salt-affected land for amelioration in the Yellow River Delta based on GIS. Acta geographica sinica 56(2):198-205

Guo QE, Wang Y, Ma Z, Guo T, Che Z, Huang G, Nan L (2011) Effect of vegetation types on soil salt ions transfer and accumulation in soil profile. Scientia Agricultura Sinica 44(13):2711-2720

Hoffman GJ, Bresler E (1986) Irrigation management for soil salinity control: theories and tests. Soil Sci Soc Am J 50(6):1552-1560

Hong S, Hendrickx J (2002) Soil salinity in arid Riparian areas. American Geophysical Union

Huang C, Xue X, Wang T, De Mascellis R, Mele G, You Q, Peng F, Tedeschi A (2011) Effects of saline water irrigation on soil properties in northwest China. Environ Earth Sci 63(4):701-708
Hussein A, Rabenhorst M (2001) Tidal inundation of transgressive coastal areas. Soil Sci Soc Am J 65(2):536-544

Johnston K (2004) Using ArcGIS geostatistical analyst. Esri, Redlands

Khosla BK, Gupta RK, Abrol IP (1979) Salt leaching and the effect of gypsum application in a saline-sodic soil. Agric Water Manag 2(3):193-202

Kotuby-Amacher J, Koenig R, Kitchen B (1997) Salinity and plant tolerance. Utah Sate University Extension

Lax A, Díaz E, Castillo V, Albaladejo J (1994) Reclamation of physical and chemical properties of a salinized soil by organic amendment. Arid Land Res Manag 8(1):9-17

Lei J, Ban N, Zahgn Y, Wang C (2011) Effects and partition characteristics of Tamarix Ramosissima on nutrients and salt of saline-alkali soils. Bulletin Soil Water Conserv 31(2):73-76

Li Y, Dongye G, Li X (2003) Countermeasure on sustainable utilization of saline soil in Yellow River Delta. J Soil Water Conserv 17(2):55-62

Li B, Xiong H, Zhang J, Long T (2010) Dynamic of soil salt in soil profiles in cultivation and its affecting actors. Acta Pedol Sin 47(3):429-438

Liu D (2004) The situation and analysis of salinity intrusion in coastal areas, China. J Geol Hazards Environ Preserv 15(1):31-36

Liu G, Drost HJ (1997) Atlas of the Yellow River delta. The Publishing House of Surveying and Mapping, Beijing

Liu Q, Liu G, Xue K, Song H (2006) Elementary analysis on characteristics of soil salinization of geomorphology units with different scales in the neoteric and modern Yellow River Delta. Chin Agric Sci Bull 22(11):353-359

Liu Q, Liu G, Zhao J (2008) The indicator function of soil type, soil texture and land type to soil salinization levels. Chin Agric Sci Bull 24(1):297-300

Liu Q, Liu G, Fan X (2010) Temporal-spatial distribution of soil salinity profile types in the Yellow River Delta. Shandong Agric Sci 1:57-62

Liu Y, Cao J, Gao Y, Liu W, Xu X (2012) The driving factors and ecological countermeasures of soil salinization in the seawater intrusion areas in the south of Laizhou Bay. Chin Agric Sci Bull 28(02):209-213

Metternicht GI, Zinck JA (2003) Remote sensing of soil salinity: potentials and constraints. Remote Sens Environ 85(1):1-20

Mondal MK, Bhuiyan SI, Franco DT (2001) Soil salinity reduction and prediction of salt dynamics in the coastal ricelands of Bangladesh. Agric Water Manag 47(1):9-23

Northey JE, Christen EW, Ayars JE, Jankowski J (2006) Occurrence and measurement of salinity stratification in shallow groundwater in the Murrumbidgee Irrigation Area, southeastern Australia. Agric Water Manag 81(1):23-40

Ren M, Walker HJ (1998) Environmental consequences of human activity on the Yellow River and its delta, China. Phys Geogr 19(5):421-432

Rhoades JD (1996) Salinity: electrical conductivity and total dissolved solids. Soil Science Society of America, American Society of Agronomy, Madison

Rhoades JD, van Schilfgaarde J (1976) An electrical conductivity probe for determining soil salinity. Soil Sci Soc Am J 40(5):647-651

Rhoades JD, Manteghi NA, Shouse PJ, Alves WJ (1989a) Estimating soil salinity from saturated soil-paste electrical conductivity. Soil Sci Soc Am J 53(2):428-433

Rhoades JD, Manteghi NA, Shouse PJ, Alves WJ (1989b) Soil electrical conductivity and soil salinity: new formulations and calibrations. Soil Sci Soc Am J 53(2):433-439

Rietz DN, Haynes RJ (2003) Effects of irrigation-induced salinity and sodicity on soil microbial activity. Soil Biol Biochem 35(6):845-854 
Sampford MR (1962) An introduction to sampling theory with applications to agriculture. Oliver and Boyd Ltd, Edinburgh

Shi C, You L, Li B, Zhang Z, Zhang O (2003) Natural consolidation of deposits and its consequences at the Yellow River Delta. Scientia Geographica Sinica 23(2):174-181

Spies BR, Woodgate P (2005) Salinity mapping methods in the Australian context: prepared for the Natural Resource Management Ministerial Council. Department of the Environment and Heritage and Department of Agriculture, Fisheries and Forestry, Australia

Team CW (2004) Electrical conductivity/salinity fact sheet, FS-3.1. 3.0 (EC). Division of Water Quality, California State Water Resources Control Board (SWRCB), Sacramento

Thomas JR, Wiegand CL (1970) Osmotic and matric suction effects on relative turgidity, temperature, and the growth of cotton leaves. Soil Sci 109:85-92

Wang Q, Shi J, Chen G, Xue L (2002) Environmental effects induced by human activities in arid Shiyang River basin, Gansu province, northwest China. Environ Geol 43(1):219-227

Wang S, Song X, Wang Q, Xiao G, Wang Z, Liu X, Wang P (2012) Shallow groundwater dynamics and origin of salinity at two sites in salinated and water-deficient region of North China Plain, China. Environ Earth Sci 66(3):729-739

Williams B, Hoey D (1987) The use of electromagnetic induction to detect the spatial variability of the salt and clay contents of soils. Soil Research 25(1):21-27

Wu Z, Zhao S, Zhang X (1994) Studies on interrelation between salt vegetation and soil salinity in the Yellow River Delta. Acta phytoecologica sinica $18(2): 184-193$

Xu X (1997) An analyses on the land structure in the Yellow River Delta. Acta Geographica Sinaca 52(1):18-26

Xue Y, Wu J, Xie C, Zhang Y (1997) Research on seawater and saltwater intrusion in Laizhou Bay. Chin Sci Bull 42(22): 2360-2368

Yang M, Liu SL, Yang ZF, Sun T, Beazley R (2009) Multivariate and geostatistical analysis of wetland soil salinity in nested areas of the Yellow River Delta. Aust J Soil Res 47(5): $486-497$
Yao R, Yang J (2007) Analysis on salinity characteristics and profile types of saline soils in the Yellow River Delta. J Arid Land Res Environ 24(1):106-112

Yao R, Yang J, Liu G, Zou P (2006) Spatial variability of soil salinity in characteristic field of the Yellow River Delta. Trans Chin Soc Agric Eng 22(6):61-66

Ye Q, Chen S, Chong H, Xue Y, Tian G, Chen S, Yn Shi, Liu Q, Liu $G$ (2007) Characteristics of landscape information Tupu of the Yellow River swings and its sub deltas during 1855-2000. Sci China Ser D Earth Sci 50(10):1566-1577

Yu J, Chen X, Sun Z, Xie W, Mao P, Wu C, Dong H, Mu X, Li Y, Guan B (2010) The spatial distribution characteristics of soil nutrients in new-born coastal wetland in Yellow River delta. Acta Sci Circum 30(4):855-861

Yu J, Fu Y, Li Y, Han G, Wang Y, Zhou D, Gao Y, Meixner FX (2011) Effects of water discharge and sediment load on evolution of modern Yellow River Delta, China, over the period from 1976 to 2009. Biogeosciences 8:2427-2435

Zarroca M, Bach J, Linares R, Pellicer XM (2011) Electrical methods (VES and ERT) for identifying, mapping and monitoring different saline domains in a coastal plain region (Alt Empordà, Northern Spain). J Hydrol 409(1-2):407-422

Zhang L, Xu H, Zhao G (2007) Salt tolerance of suaeda salsa and its soil ameliorating effect on coastal saline soil. Soils 39(2):310-313

Zhang X, Ye S, Yin P, Chen D (2009) Characters and successions of natural wetland vegetation in Yellow River Delta. Ecol Environ Sci 18(1):292-298

Zhang T, Zeng S, Gao Y, Ouyang Z, Li B, Fang C, Zhao B (2011) Assessing impact of land uses on land salinization in the Yellow River Delta, China using an integrated and spatial statistical model. Land Use Policy 28(4):857-866

Zhao X, Cui B, Sun T, He Q (2010) The relationship between the spatial distribution of vegetation and soil environmental factors in the tidal creek areas of the Yellow River Delta. Ecol Environ Sci 19(8):1855-1861

Zheng Z, Zhang F, Ma F, Chai X, Zhu Z, Shi J, Zhang S (2009) Spatiotemporal changes in soil salinity in a drip-irrigated field. Geoderma 149(3-4):243-248 